Раздел 3. Физика горных процессов на больших глубинах

УДК 622.841:622.833.5:622.281.74 https://doi.org/10.37101/ftpgp22.01.006

ЧИСЕЛЬНИЙ АНАЛІЗ МОДЕЛІ САМОНАГРІВАННЯ ВУГІЛЛЯ У ЩІЛЬНОМУ МАСИВІ ГІРСЬКИХ ПОРІД

\author{
Е.П. Фельдман ${ }^{1 *}$, Н.О. Калугіна ${ }^{1}$, О.В. Чеснокова ${ }^{1}$ \\ ${ }^{1}$ Інститут фізики гірничих процесів Національної академії наук України, \\ м. Дніпро, Україна \\ *Відповідальний автор: e-mail: edward.feldman.40@gmail.com
}

\title{
NUMERICAL ANALYSIS OF THE COAL SELF-HEATING MODEL IN A DENSE ROCK MASSIF
}

\author{
E.P. Feldman ${ }^{1 *}$, N.O. Kalugina ${ }^{1}$, O.V. Chesnokova ${ }^{1}$ \\ ${ }^{1}$ Institute for Physics of Mining Processes of the National Academy of Sciences of \\ Ukraine, Dnipro, Ukraine \\ *Corresponding author: edward.feldman.40@gmail.com
}

\begin{abstract}
Purpose. A numerical analysis of the processes of self-heating of a coal massif section on the basis of a mathematical model that takes into account the tight contact of coal with the rock at great depths of the formation and conditions when the heat of the chemical reaction of coal oxidation is transferred to the environment (enclosing rocks) only by the heat conduction mechanism.

Methods. This work is based on solving the equations of thermodynamics by numerical methods using mathematical computer programs.

Findings. As a result of a numerical analysis of the constructed mathematical model of coal self-heating in a compact coal mass in the presence of an oxygen source near the bed, the results of an asymptotic analysis confirming that the temperature of the coal rises, albeit slowly, but unlimitedly, and reaching the constant temperature mode for all, the value of the coefficient of heat transfer and thermal diffusivity of the rock is absent.
\end{abstract}

Originality. By numerical calculations, the theoretical model of coal self-heating in a dense rock mass is studied, when the heat of the chemical reaction of coal oxidation is transferred to the host rocks only by the heat conductivity mechanism. The calculations were carried out for the case when the host rocks are heated near the surface of their contact with coal and the density of the heat flow from coal to rock is determined by the difference in the contact temperatures of coal and rock.

Practical implications. The results obtained can be useful for updating the fire hazard forecast under appropriate environmental conditions. They allow us to describe the process of low-temperature self-heating of compact coal seams over a 
wide range of changes in the basic thermophysical parameters of coal and rocks, and can be the basis for predicting the endogenous fire hazard at great depths. Keywords: coal, oxygen, self-heating, spontaneous combustion, fire.

\section{1. ВСТУП}

Аналіз аварій на вугледобувних підприємствах показує, що на пластах, схильних до самозаймання, внаслідок неправильного ведення гірських робіт, недосконалості профілактичних заходів і невдалого їх застосування можуть виникнути ендогенні пожежі. Одним із завдань прогнозу ендогенної пожежонебезпеки є встановлення її очікуваної величини на виїмкових полях (ділянках) в залежності від гірничо-геологічних умов залягання пласта і гірничо-технічних умов відпрацювання. Визначення обсягу загальнотехнічних i спеціальних заходів профілактики для запобігання пожеж повинно виконуватися тільки після визначення схильності шахтопласта до самозаймання, аналізу гірничо-технічних факторів, що перешкоджають або сприяють виникненню або поширенню пожежі, і потенційних умов для гасіння. Методики прогнозу пожежонебезпеки, що існують, не дають однозначної відповіді про місцезнаходження джерела самозаймання і схильності вугільного пласта до самозаймання. На цей час немає єдиної загальновизнаної теорії самозаймання вугілля, тому вивчення кінетики процесу переходу самонагрівання у самозаймання з урахуванням взаємодії вугілля з оточуючими породами та формування осередку ендогенної пожежі у вугільних пластах і породних відвалах є актуальною науковою задачею.

\section{2. ПОСТАНОВКА ЗАДАЧІ}

Самонагрівання вугілля у щільному гірському масиві внаслідок екзотермічної реакції окислення вуглеводневої маси можливе за рахунок доступу кисню через фільтраційні канали як в уміщальних породах, так і в самому вугіллі. Джерелом кисню (повітря), яке для будь-якого помітного розігріву повинно знаходитися поблизу пласта, може бути вентиляційний штрек, розташований на сусідньому з пластом горизонті або область крупноамплітудного геологічного порушення, наприклад, насув. Тепловий баланс такого вугільного масиву регулюється співвідношенням тепловиділення і тепловідведення (тепловіддачі), основну роль у якому грає теплопередача від вугілля в уміщальні породи.

Якщо позначити $t_{d}$ - час «доставки» кисню від джерела до вугілля, то він буде дорівнювати $t_{d}=\frac{l_{0}^{2}}{D_{f}}$, де $D_{f}-$ середньозважений коефіцієнт фільтрації, $l_{0}$ - відстань, на якій знаходиться джерело кисню з об'ємною часткою $c_{0}$ від досліджуваної ділянки вугільного пласта. Відповідно, швидкість зміни концентрації $c$ кисню у вугіллі за рахунок надходження від джерела $s$ :

$$
\left.\frac{d c}{d t}\right|_{S}=\frac{c_{0}-c}{t_{d}}
$$


Для грубої оцінки часу «доставки» можна прийняти $l_{0} \sim 1 \mathrm{M}, D_{f} \sim 3 \cdot 10^{-5} \mathrm{M}^{2} /$ сек [1], тому $t_{d}$ порядку десяти годин.

Для випадку, коли теплота хімічної реакції окислення вугілля передається в навколишнє середовище (уміщальні породи) тільки за механізмом теплопровідності в [2] було побудовано математичну модель самонагрівання ділянки вугільного масиву, віддаленої від вибою. В моделі густина теплового потоку з вугілля в породу визначається не різницею температур вугілля $\mathrm{i}$ усередненої температури оточуючих порід, а, за законом Ньютона, різницею приконтактних температур вугілля і породи.

Для дослідження розвитку процесу самонагрівання пожежонебезпечної ділянки вугільного пласта було побудовано систему рівнянь, яка у безрозмірному вигляді наступна:

$$
\left\{\begin{array}{l}
f(t)=\int_{0}^{t} c(\tau)(\beta+\eta f(\tau)) d \tau-P \int_{0}^{t} \frac{f(\tau) d \tau}{\sqrt{t-\tau}} \\
\frac{d c}{d t}=c_{0}-c(t)-(\beta+\eta f(\tau)) c(t)
\end{array}\right.
$$

де функція $f(t)$ - шуканий приріст температури $\Theta(t)-\Theta_{0} \equiv f(t), t-$ час, $\Theta-$ нормована температура, яка вимірюється в одиницях $T_{*} \equiv \frac{q \Pi}{C_{v}}$ і відраховується від $T_{0}$ (де $T_{r}$ - температура уміщальної породи безпосередньо на поверхні контакту, $T$ - абсолютна температура вугілля, $\left.T(0)=T_{r}(0)=T_{0}\right), q-$ тепловий ефект реакції у розрахунку на одиницю об'єму кисню, П- пустотність масиву, $C_{v}$ - питома теплоємність вугілля у розрахунку на одиницю об'єму,

$$
\beta \equiv U_{0} \cdot t_{d}, \quad \eta \equiv E \cdot T_{*} \cdot t_{d}, \quad P \equiv \frac{2 \sqrt{a_{r} \cdot t_{d}} \cdot C_{r}}{\sqrt{\pi} \cdot C_{v} \cdot h}
$$

теплофізична характеристика $U_{0}$ - це константа швидкості сорбції кисню при $T=T_{0}$, величина $E$ - температурний коефіцієнт швидкості сорбції, вона характеризує зростання швидкості хімічної реакції окислення вугілля з температурою, $h$ - товщина пласта, $a_{r}$ - коефіцієнт температуропровідності породи, $\alpha$ - коефіцієнт тепловіддачі від вугілля до породи, $C_{r}-$ теплоємність породи.

Початкові умови цієї системи: $f(0)=0, c(0)=0$.

\section{3. МЕТОДИ ДОСЛІДЖЕННЯ}

На великих глибинах гірничий тиск сильно здавлює вугілля разом з породою, що вміщує. Отже, механічний, а значить, і тепловий контакти стають набагато щільніше, так що $\alpha$ може збільшуватися в кілька разів, пропорційно глибині залягання. Асимптотичний аналіз системи [3] показав, що в цьому випадку для грубої оцінки температури небезпечної ділянки пласта можна користуватися формулою 


$$
\Theta(t)-\Theta_{0} \equiv f(t) \approx \frac{c_{0} t}{1+p \sqrt{t}} \sim \frac{c_{0}}{p} \sqrt{t}
$$

При цьому на великих часах концентрація кисню в пласті $\left.\mathrm{c}(t)\right|_{t \rightarrow \infty} \rightarrow 0$.

Отримана залежність показує, що при зроблених припущеннях, температура необмежено зростає, хоча швидкість зростання температури убуває 3 часом $\frac{1}{\sqrt{t}}$. При стандартних значеннях теплофізичних характеристик і при $h \sim 1$ м і $T_{0}=40^{\circ} \mathrm{C}$ температура досягне критичної величини для самозаймання $\left(\sim 100^{\circ} \mathrm{C}\right)$ за час порядку десятка діб або навіть декількох місяців. Асимптотичний аналіз системи рівнянь (1) - (2) потверджується результатами іï чисельного рішення.

\section{4. РЕЗУЛЬТАТИ ДОСЛІДЖЕННЯ}

Чисельне рішення системи (1)-(2) було виконано за допомогою комплексу математичних програм. Для проведення цього рішення необхідно перш за все вибрати значення $t_{d}=\frac{l_{0}^{2}}{D}$. Якщо рахувати $l_{0} \sim 1 \mathrm{M}$, а коефіцієнт фільтрації $\mathrm{D}=10^{-4} \mathrm{M}^{2} /$ сек, то $t_{d} \sim 10^{4}$ сек 3 г. Далі $з$ літератури [4] відомі масштаби па-

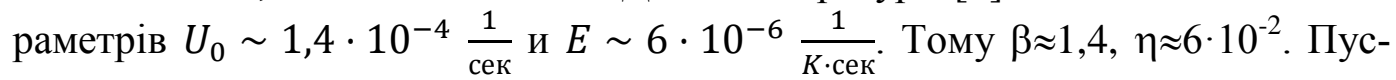
тотність $\Pi=5 \cdot 10^{-2}$. Температуропровідність породи $a_{r} \sim 1,6 \cdot 10^{-7} \frac{\mathrm{m}^{2}}{\text { сек }}$, теплоємність вугілля того ж порядку, що $\mathrm{i}$ теплоємність породи: $\mathrm{C}_{v} \sim \mathrm{C}_{r} \sim 1,2 \cdot 10^{6} \frac{\text { Дж }}{\mathrm{m}^{3} \cdot \mathrm{K}}, h \sim 1 \mathrm{м}, c_{0} \sim 0,21$. Калібрована температура $T * \approx 0,5 \mathrm{~K}$.

Зрозуміло, при чисельному рішенні і побудові графіків майже всі ці параметри варіювалися в широких межах. Результати чисельного рішення системи (1)-(2) для представницьких значень, що входять в рівняння характеристик і параметрів представлені на рис. 1.

\section{5. ОБГОВОРЕННЯ РЕЗУЛЬТАТІВ}

3 розгляду цих рисунків можна зробити наступні висновки. По-перше, концентрація кисню $c(t)$ на великих часах завжди наближається до нуля. Подруге, і це основний результат, температура вугілля монотонно зростає, формально до нескінченності, приблизно по кореневому закону, тобто на великих часах $T(t)-T_{0}$ пропорційно $\sqrt{t}$. Виходу на стаціонарний режим немає ні при яких значеннях характеристик і параметрів. По-третє, величина параметрів $\beta$ і $\eta$, що характеризують швидкість і температурний приріст швидкості реакції окислення вугілля відповідно, лише незначно змінює хід температури на великих часах. 

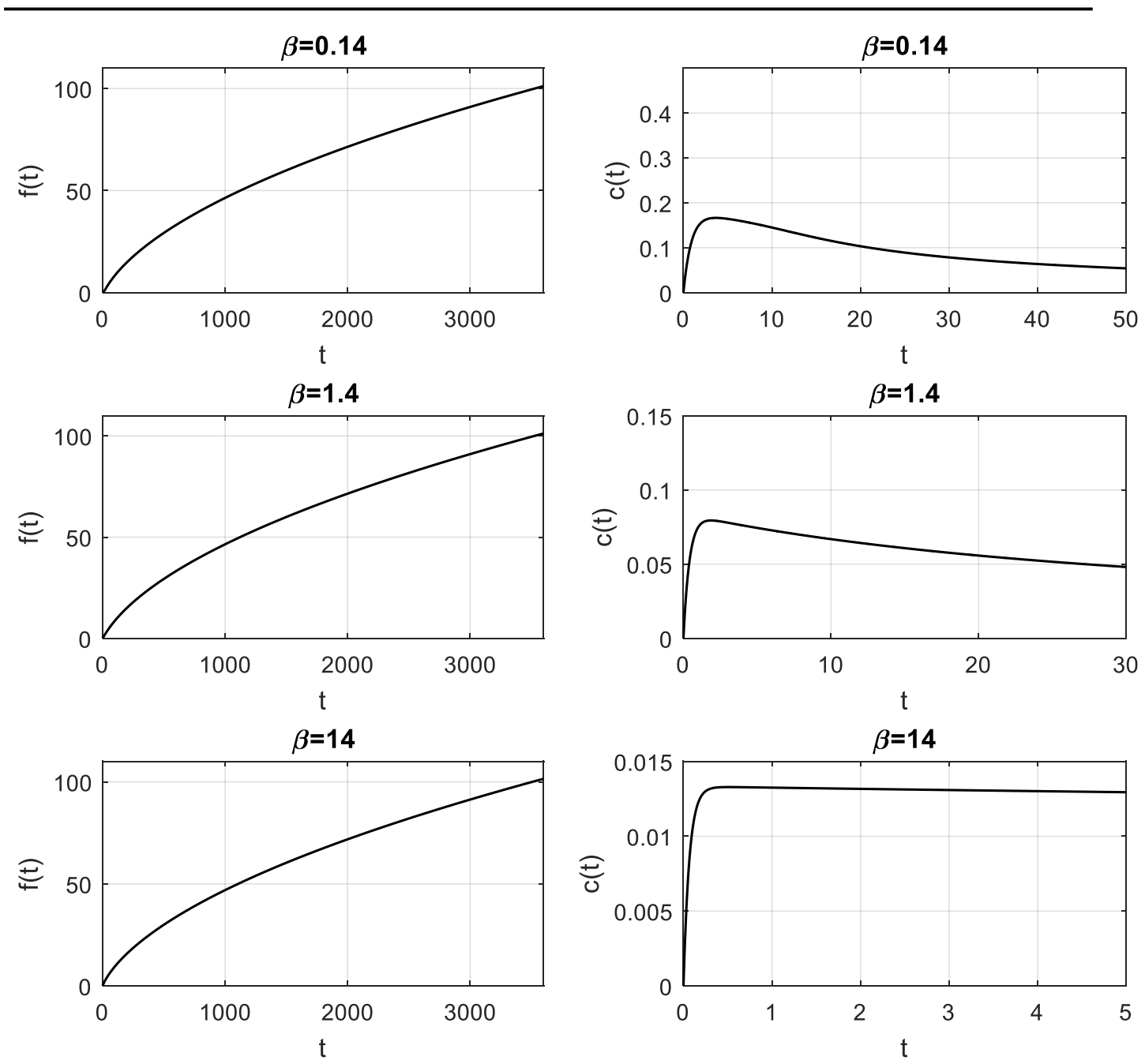

Рисунок 1. Чисельне рішення системі (1)-(2)

3 наведених графіків можна, хоча і грубо, оцінити часи досягнення критичної температури нагріву $T_{c r} \sim 100^{\circ} \mathrm{C}$, коли самонагрівання переходить у самозаймання. Це час порядку року при $t_{d}=10^{4} \mathrm{c}$ і він збільшується із з зростанням $t_{d}$. Іншими словами, нагрів вугілля йде дуже повільно. Проте, виникнення джерела самозаймання можливе, що показує і статистика пожеж на великих глибинах. Час «очікування» пожежі може сильно зменшитися, до двох - трьох місяців, зі зменшенням $t_{d}$ і зменшенням температуропровідності породи $a_{r}$.

\section{6. ВИСНОВКИ}

В результаті чисельного аналізу побудованої моделі самонагрівання вугілля в компактному масиві виявлено, що при розігріві приконтактної ділянці породи тепловий потік з вугілля зменшується і тому температура вугілля зростає настільки, що зникає стаціонарний режим. Підтверджено результати асимптотичного аналізу моделі у тому, що температура вугілля зростає, хоча і повільно, але необмежено, і вихід на режим постійної температури відсут- 
ній, взагалі кажучи, при всіх значеннях коефіцієнта тепловіддачі і температуропровідності породи $a_{r}$.

Для уточнення прогнозу пожежонебезпеки при відповідних зовнішніх умовах i, взагалі, для опису процесу низькотемпературного самонагрівання компактних вугільних пластів слід скористатися чисельним рішенням системи трьох рівнянь для концентрації кисню $c$, температури вугілля $T$ і температури приконтактного шару породи $T_{r}$. Ця система «працює» на дуже широкому інтервалі зміни основних теплофізичних параметрів вугілля і порід, що вміщають, і може бути покладена в основу прогнозу пожежонебезпеки на великих глибинах.

\section{СПИСОК ЛІТЕРАТУРИ}

1. Щербань А.Н., Кремнев О.А. (1951). Исследование коэффициентов теплопроводности в моделях горных выработок, Киев: Из-во АН УССР.

2. Фельдман, Е.П., Калугіна, Н.О., \& Чеснокова, О.В. (2018) Математична модель теплопереносу у вугільному пласті на великих глибинах. Фізико-технічні проблеми гірничого виробнищтва, (20), 9-14.

3. Фельдман, Е.П., Калугіна, Н.О., \& Чеснокова, О.В. (2019) Асимптотичний аналіз моделі самонагрівання вугілля. Можливості прогнозу пожежонебезпеки. $\Phi i-$ зико-технічні проблеми гірничого виробництва, (21), 106-115.

4. Веселовский В.С., Виноградова Л.П., Орлеанская Г.Л. (1972). Физические основы самовозгорания угля и руд. Москва: Наука.

\section{REFERENCES}

1. Shcherban' A.N., Kremnev O.A. (1951). Issledovaniye koeffitsiyentov teploprovodnosti v mo-delyakh gornykh vyrabotok, Kyiv: Iz-vo AN USSR.

2. Feldman, E.P., Kalugina, T.O., \& Chesnokova, O.M. (2018) Matematychna model' teploperenosu u vuhil'nomu plasti na velykykh hlybynakh. Fizyko-tekhnichni problemy hirnychoho vyrobnytstva, (20), 9-14.

3. Feldman, E.P., Kalugina, T.O., \& Chesnokova, O.M. (2019) Asymptotychnyy analiz modeli samonahrivannya vuhillya. Mozhlyvosti prohnozu pozhezhonebezpeky. Fizyko-tekhnichni problemy hirnychoho vyrobnytstva, (21), 106-115.

4. Veselovskiy V.S., Vinogradova L.P., Orleanskaya G.L. (1972). Fizicheskiye osnovy samovozgoraniya uglya i rud. Moskva: Nauka.

\section{ABSTRACT (IN UKRAINIAN)}

Мета. Чисельний аналіз процесів самонагрівання ділянки вугільного масиву, віддаленої від вибою, на основі математичної моделі, що враховує випадок щільного контакту вугілля з породою на великих глибинах розташування пласта і умов, коли теплота хімічної реакції окислення вугілля передається в навколишнє середовище (уміщальні породи) тільки за механізмом теплопровідності.

Методика. Робота виконана на основі рішення рівнянь термодинаміки чисельними методами за допомогою математичних комп'ютерних програм.

Результати. В результаті чисельного аналізу побудованої моделі самонагрівання вугілля в компактному гірському масиві підтверджено результати 
асимптотичного аналізу у тому, що температура вугілля зростає, хоча і повільно, але необмежено, і вихід на режим постійної температури відсутній при всіх значеннях коефіцієнта тепловіддачі і температуропровідності породи Наукова новизна. Шляхом чисельних методів, досліджено теоретичну модель самонагрівання вугілля у щільному масиві гірських порід, коли теплота хімічної реакції окислення вугілля передається в навколишнє середовище (уміщальні породи) за механізмом теплопровідності. Розрахунки проведені для випадку, коли уміщальні породи розігріваються поблизу поверхні їх контакту з вугіллям і густина теплового потоку з вугілля в породу визначається різницею приконтактних температур вугілля і породи.

Практична значимість. Отримані результати можуть бути корисні для уточнення прогнозу пожежонебезпеки при відповідних зовнішніх умовах. Вони дозволяють описати процес низькотемпературного самонагрівання компактних вугільних шарів на широкому інтервалі зміни основних теплофізичних параметрів вугілля і порід, що вміщують, і можуть бути покладені в основу прогнозу ендогенної пожежонебезпеки на великих глибинах.

Ключові слова: вугілля, кисень, самонагрівання, самозаймання, пожежа.

\section{ABSTRACT (IN RUSSIAN)}

Цель. Численный анализ процессов самонагревания участка угольного массива на основе математической модели, учитывающей случай плотного контакта угля с породой на больших глубинах расположения пласта и условий, когда теплота химической реакции окисления угля передается в окружающую среду (вмещающие породы) только по механизму теплопроводности.

Методика. Работа выполнена на основе решения уравнений термодинамики численными методами с помощью математических компьютерных программ.

Результаты. В результате численного анализа построенной математической модели самонагревания угля в компактном угольном массиве при наличии источника кислорода вблизи пласта подтверждены результаты асимптотического анализа о том, что температура угля растет, хотя и медленно, но неограниченно, и выход на режим постоянной температуры отсутствует при всех значение коэффициента теплоотдачи и температуропроводности породы.

Научная новизна. Путем численных расчетов исследована теоретическая модель самонагревания угля в плотном массиве горных пород, когда теплота химической реакции окисления угля передается во вмещающие породы только по механизму теплопроводности. Расчеты проведены для случая, когда вмещающие породы разогреваются вблизи поверхности их контакта с углем и плотность теплового потока из угля в породу определяется разницей приконтактных температур угля и породы.

Практическая значимость. Полученные результаты могут быть полезны для уточнения прогноза пожароопасности при соответствующих внешних условиях. Они позволяют описать процесс низкотемпературного самонагревания компактных угольных пластов на широком интервале изменения ос- 
новных теплофизических параметров угля и пород, и могут быть положены в основу прогноза эндогенной пожароопасности на больших глубинах.

Ключевые слова: уголь, кислород, самонагревание, самовозгорание, пожар.

\section{ABOUT AUTHORS}

Feldman Edward, Doctor of Physical and Mathematical Sciences, Professor, Chief Researcher, Department of Physics of Coal and Rock, Institute for Physics of Mining Processes of the National Academy of Sciences of Ukraine, 2A Simferopolskaya Street, Dnipro, Ukraine, 49600. E-mail: edward.feldman.40@gmail.com

Kalugina Nadiia, Doctor of Technical Sciences, Scientific Secretary of the Institute for Physics of Mining Processes of the National Academy of Sciences of Ukraine, 2A Simferopolskaya Street, Dnipro, Ukraine, 49600. E-mail: kalugina_n_a@ukr.net

Chesnokova Oksana, Candidate of Technical Science, Researcher, Department of Physics of Coal and Rock, Institute for Physics of Mining Processes of the National Academy of Sciences of Ukraine, 2A Simferopolskaya Street, Dnipro, Ukraine, 49600. E-mail: chesnokova0507@gmail.com 